\section{Commentary: Delayed stenting for arch dissection}

\author{
John Bozinovski, MD, MSc
}

The results from the treatment of chronic aortic arch dissection using a novel, single-branched customized stent graft were previously reported in $2015 .{ }^{1}$ Updated long-term results are reported. ${ }^{2}$ Zhang and colleagues ${ }^{2}$ treated 51 patients with chronic aortic arch dissection (all but one were in the subacute phase at intervention) between 2009 and 2014. Thirteen patients had entry tears in zones 0 or 1 and required multiple stents or fenestrations to preserve branch artery perfusion. The strengths of the study include the assessment of a nonconventional treatment for the disease process, the median follow-up of nearly 4 years, and that all patients were accounted for through follow-up. Only one aortic-related death occurred in the perioperative period and one in the follow-up period. Three aortic-related nonfatal events occurred in the follow-up period and 2 were intervened upon.

At 1 year, and continuing to the end of a median followup of 92 months, the absolute size of the aorta decreased at all arch levels measured. This was accompanied by an increase in the diameter of the true lumen and a decrease in the diameter of the false lumen. Such findings are in keeping with those found in chronic type B dissections treated with stenting and described in the Investigation of Stent Grafts in Aortic Dissection with extended length of follow-up (INSTEAD-XL) trial. ${ }^{3}$

The study by Zhang and colleagues ${ }^{2}$ included type $\mathrm{A}$ and $B$ dissections and therefore different indications for intervention and could have benefited from stricter patient selection criteria. Criteria used to exclude patients who would otherwise be considered for open surgical intervention were not absolute and included age $>70$ years, redo surgery, American Society of Anesthesia class $>$ IV, New York Heart Association class III/IV, and severe chronic obstructive

From the Division of Cardiac Surgery, The Ohio State University Wexner Medical Center, Columbus, Ohio.

Disclosures: Author has nothing to disclose with regard to commercial support.

Received for publication Oct 25, 2019; revisions received Oct 25, 2019; accepted for publication Oct 26, 2019; available ahead of print Nov 20, 2019.

Address for reprints: John Bozinovski, MD, MSc, N816A Doan Hall, 410 West 10th Ave, Columbus, OH, 43210 (E-mail: jovan.bozinovski@osumc.edu).

J Thorac Cardiovasc Surg 2021;162:23-4 0022-5223/\$36.00

Copyright (c) 2019 Published by Elsevier Inc. on behalf of The American Association for Thoracic Surgery

https://doi.org/10.1016/j.jtcvs.2019.10.173

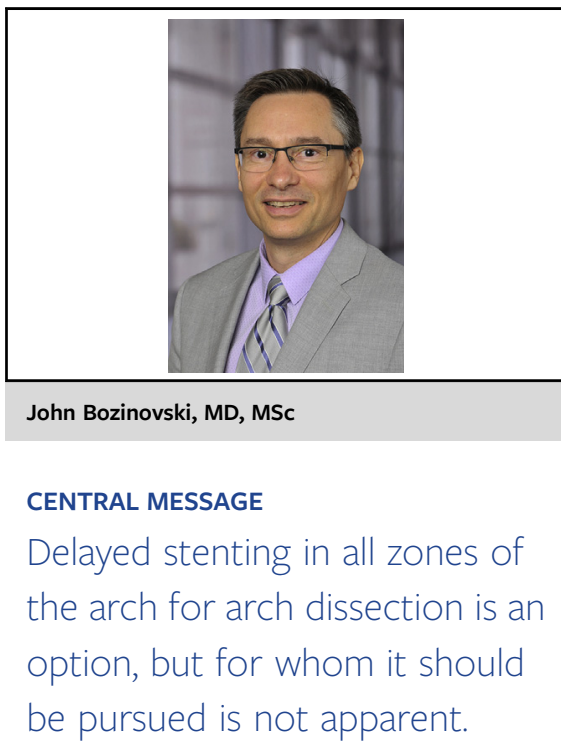

pulmonary disease or renal insufficiency. These are found in many patients with type A dissection who undergo surgery, although in the subacute/chronic dissection patient such characteristics would give cause to consider options other than open surgical treatment.

The time from suspected onset of dissection to intervention was 31 to 72 days (median time 39 days). It was not made clear but, because the median time for graft customization was 22 days, some of these patients could have been in the acute phase at the time of presentation and were sufficiently stable to be treated conservatively while awaiting stent production. Characteristics that made them conducive to delayed treatment were not delineated. Considering that no patient died or proceeded to open surgical intervention while awaiting graft customization, and that the aorta was not dilated significantly in these patients (the proximal aorta ranged in size from 28 to $40 \mathrm{~mm}$, and distal aorta ranged in size from 25 to $38 \mathrm{~mm}$ ), the possibility that they could have continued with conservative treatment is apparent, especially in the type B dissections. Thus, it might not be appropriate to compare these patients with what might be expected in open surgical patients.

The authors suggest this approach provides a satisfactory and promising alternative treatment option for open surgery. That may be so for the non-type A dissection patients but there are patients for whom this approach is not currently possible. An excessively dilated aorta and the need for immediate intervention to address ischemia preclude this approach. In the remaining patients, knowing which of the type A dissections may tolerate a delay for their tailored device is not obvious. 


\section{References}

1. Lu Q, Feng J, Zhou J, Zhao Z, Li H, Teng Z, et al. Endovascular repair by customized branched stent-graft: a promising treatment for chronic aortic dissection involving the arch branches. J Thorac Cardiovasc Surg. 2015;150: 1631-8.e5.
2. Zhang L, Qingsheng L, Zhu H, Jing Z. Branch stent-grafting for endovascular repair of chronic aortic arch dissection. J Thorac Cardiovasc Surg. 2021;162:12-22.e1.

3. Nienaber CA, Kische S, Rousseau H, Effebrecht H, Rehders TC, Kundt G, et al. Endovascular repair of type $\mathrm{B}$ aortic dissection: long term results of the randomized investigation of stent grafts in aortic dissection trial. Circ Cardiovasc Interv. 2013;6:407-16.
See Article page 12.

\section{Commentary: Branches of life}

\author{
Jihoon Kim, MD, $\mathrm{PhD},{ }^{a}$ and \\ Joon Bum Kim, MD, $\mathrm{PhD}^{\mathrm{b}}$
}

"I'd rather die."
With accumulating experiences, the contemporary open repair for both acute and chronic aortic dissection has yielded favorable outcomes. On the other hand, about $10 \%$ of the candidates for emergency aortic operation are considered "inoperable" because of age and comorbidities. ${ }^{2}$ The postoperative major complication risks might also affect the patient's decision, as in Dr DeBakey's own experience as a patient. ${ }^{1}$ Meanwhile, the in-hospital mortality of the patients with medically managed type A aortic dissection ranged from $48.6 \%$ to $64.9 \%$ according to the International Registry of Acute Dissection database during the last 2 decades. ${ }^{3}$ In this context, the development of the interventional treatment for the ascending aorta and the aortic arch pathology will be of great value, especially to these inoperable patients.

In this issue of the Journal, Zhang and colleagues ${ }^{4}$ report the long-term results of the customized, branched stentgraft insertion for the patients with aortic arch dissection who had been classified as being at "high risk for open

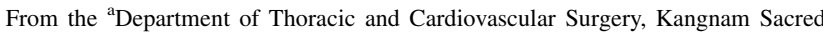
Heart Hospital, Hallym University Medical Center, Hallym University College of Medicine, Seoul, Republic of Korea; and ${ }^{\mathrm{b}}$ Department of Thoracic and Cardiovascular Surgery, Asan Medical Center, University of Ulsan College of Medicine, Seoul, Republic of Korea.

No funding was provided for this article.

Disclosures: Authors have nothing to disclose with regard to commercial support.

Received for publication Oct 24, 2019; revisions received Oct 24, 2019; accepted for publication Oct 25, 2019; available ahead of print Nov 13, 2019.

Address for reprints: Joon Bum Kim, MD, PhD, Department of Thoracic and Cardiovascular Surgery, Asan Medical Center, University of Ulsan College of Medicine, 88, Olympic-Ro 43-Gil, Songpa-Gu, Seoul, 05505, Republic of Korea (E-mail: jbkim1975@amc.seoul.kr).

J Thorac Cardiovasc Surg 2021;162:24-5

0022-5223/\$36.00

Copyright (c) 2019 by The American Association for Thoracic Surgery

https://doi.org/10.1016/j.jtcvs.2019.10.140
Check for updates

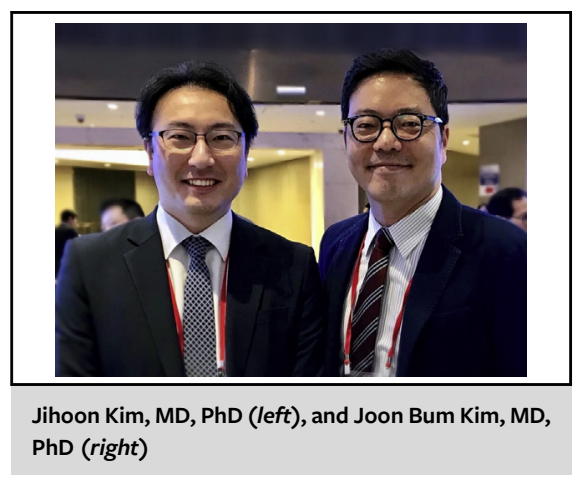

CENTRAL MESSAGE

Despite the challenging pathoanatomy, the ascending aorta and the aortic arch interventions are constantly developing and surgery" opening doors for patients previously considered inoperable.

$(\mathrm{n}=51)$ between 2009 and 2014, as a follow-up to their initial 5-year outcome reports published in 2015 . $^{5}$ The most frequent procedure was a single-branched stent-graft insertion $(n=22)$ in which the branch of the graft was placed to the left subclavian artery $(n=18)$. The rest of the patients were treated with various modifications, such as fenestrations and overlapping 2 grafts. Concomitant cervical bypass operations were also performed in 11 patients.

During the follow-up period (median of 92 months), the aorta showed positive remodeling, with no type I or III endoleak, and the incidences of complication $(0.035 \% / \mathrm{pa}-$ tient-y), reintervention (0.015\%/patient-y), all-cause mortality $(0.020 \% /$ patient-y) and aorta-related mortality $(0.010 \% /$ patient-year) were acceptable. There were 4 deaths in total, and the causes were retrograde type A dissection $(n=2)$, cerebral infarction $(n=1)$, and cancer $(\mathrm{n}=1)$. 